\title{
Preoperative sterilization of the perineum: A comparison of six antiseptics
}

\author{
MARGARET E. BYATT AND A. HENDERSON \\ From the Research Department, Royal Maternity Hospital, Glasgow
}

SYNOPSIS Nine preparations of six antiseptic substances were applied to the perineum of pregnant women at term in order to assess their efficacy in sterilizing the skin. The efficacy, in descending order of effectiveness, after three minutes' exposure, was $p$-chlor- $m$-xylenol in alcohol (surgical Dettol); chlorhexidine gluconate in detergent (Hibiscrub), followed by the aqueous preparations p-chlor-m-xylenol (Dettol), chlorhexidine gluconate (Hibitane), cetrimide (Cetavlon), povidoneiodine (Disadine), benzalkonium chloride (Resiguard), and merthiolate. Surgical Dettol was the only alcohol-based preparation used.

Although antiseptics are applied routinely to the skin before operation, little knowledge exists of their efficacy in sterilizing the operation site. Work in vitro reflects only poorly the condition existing on the skin, as each site of the body presents different problems; the present work describes the effect of six commonly used antiseptics when applied to the perineum at the site of an episiotomy operation.

\section{Patients and Methods}

Sixty-seven patients were examined on admission to the Glasgow Royal Maternity Hospital, all in labour or near term. At the time of examination, the vulva had not been shaved nor had the patients been bathed in hospital.

The antiseptics tested are shown in table I.

Received for publication 31 August 1973.
Each preparation was used at that concentration recommended by the manufacturers. In one instance -chlorhexidine gluconate in the form of the hand cleanser Hibiscrub-this meant applying the undiluted antiseptic to the vulva as a solution of $20 \%$ (v/v) Hibitane gluconate (equivalent to chlorhexidine gluconate $4 \% \mathrm{w} / \mathrm{v}$ ) and then rinsing off with water as in washing the hands. Two preparations of Dettol were used: an aqueous solution intended for general antiseptic purposes, and an alcoholic solution devised for preoperative skin cleansing.

In order to determine the number of bacteria on a given area of skin, a velvet pad, $2 \mathrm{~cm}$ diameter, glued to a wooden rod was applied to the vulva in the episiotomy area, then impressed on a horse blood nutrient agar plate. In all cases studied, the episiotomy area and a corresponding area on the opposite side of the vulva were each sampled as described (sites $\mathrm{C}$ and $\mathrm{A}$ in fig 1 ). Test site $\mathrm{C}$ was then

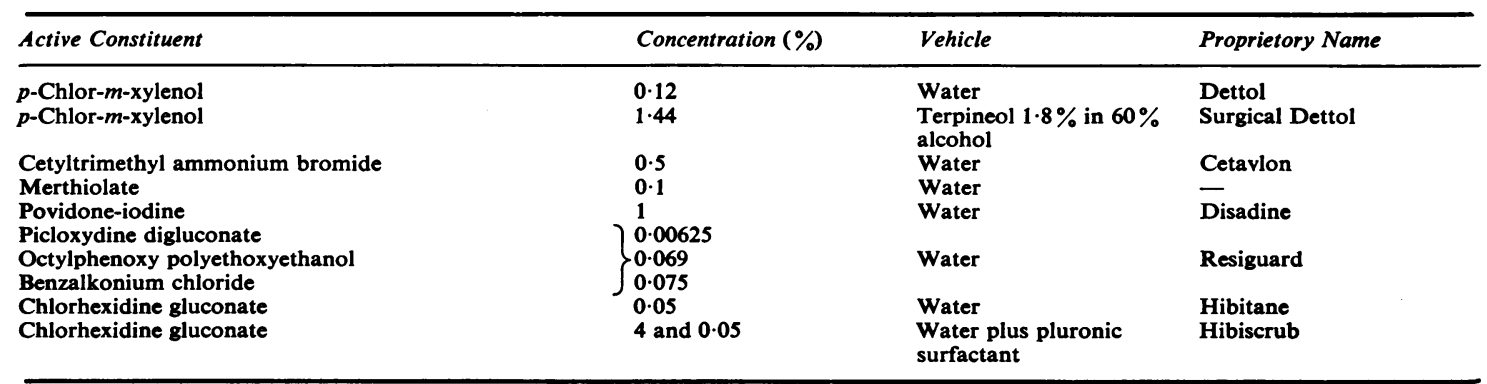


washed with $25 \mathrm{ml}$ of antiseptic applied with three cottonwool swabs as in preoperative cleansing; similarly site A was washed with water. After three minutes these areas were resampled (sites D and B in fig 1).

Preliminary tests performed on several patients other than the 67 cases studied revealed that the incorporation of antiseptic neutralizers (lecithin and tween) in the agar did not affect the results and it was concluded that the culture medium itself neutralized any small amount of antiseptic carried over on the pads.

Each antiseptic was tested on a minimum of six patients.

Incubation of culture plates was overnight at $37^{\circ} \mathrm{C}$. All plates were then photographed for the purpose of comparison.

The number of colonies present on each area tested was counted before and after application of the various antiseptics. Counts of more than 100 were considered to equal 100 exactly. If more than 100 colonies were present after treatment, the effectiveness of that antiseptic was taken as nil. The effect of treatment for each patient was estimated from the difference in counts before and after exposure to the antiseptic.

The effect of washing with water was estimated in a similar manner and was found to cause a significant decrease in the bacterial count. As a result, the total decrease in bacterial population where an antiseptic has been used cannot be attributed solely to its sterilizing action, as rubbing with sterile cottonwool swabs and water causes a significant reduction. Because of the significant effect of this 'mechanical' removal of bacteria, instances having less than 10 colonies initially were omitted from the series.

\section{Results}

Of the 67 women examined 13 were omitted from the series on account of low initial bacterial population, ie, less than 10 colonies recovered on the area sampled, leaving 54 patients.

Table II shows the average percentage reduction for each antiseptic in order of apparent effectiveness and for the 54 control tests when each perineum was washed with water. By far the most effective were alcoholic (surgical) Dettol and concentrated Hibiscrub.

Among the 67 women examined, considerable variation was found in the bacterial count of the vulva, some being nearly free of bacteria and others heavily populated (fig 2 ).

It is of interest to note that, contrary to expectation, pathogenic bacteria were rarely found. The predominant organisms were Staphylococcus epider-

\begin{tabular}{rll}
\hline No. of Patients & Antiseptic & $\begin{array}{l}\text { Average Reduction } \\
\text { in Bacterial } \\
\text { Population (\%) }\end{array}$ \\
\hline 1 & Dettol (alcoholic) & 100 \\
6 & Hibiscrub (concentrated) & 98 \\
6 & Hibiscrub (diluted) & 82 \\
6 & Dettol (aqueous) & 77 \\
6 & Hibitane & 68 \\
6 & Cetavlon & 63 \\
6 & Disadine & 60 \\
6 & Resiguard & 54 \\
6 & Merthiolate & 28 \\
Total 54 & Water as control & 24 \\
54 & . & \\
\hline
\end{tabular}

Table II Reduction in bacterial population after appl cation of antiseptic for three minutes

mis and cutaneous Corynebacterium. In only two instances was Escherichia coli found and in only three was Staphylococcus aureus recovered. Other aerobic faecal organisms such as Proteus and Streptococcus faecalis were not found.

In fig 3 is illustrated a typical result.

\section{Discussion}

Antiseptics are regarded as having an important role in the prevention and treatment of operation woung sepsis but most comparative work has been per formed by in-vitro methods. One reason for this that there is no universally accepted method for their comparison in vivo. The test tube methods applied to disinfectants have been extended to antiseptics, eg, the Rideal-Walker test (1921), the Chick-Martin test (1938), and, more recently, Kelsey's test (Kelsey, Beeby, and Whitehouse, 1965). Although these methods were developed to compare the efficacy of disinfectants rather than antiseptics, manufacturers quote the results of these tests as being indicative of the activity of the latter also. Ideally, antiseptics should be tested on the site where they will be used, but methods which dispense with the use of the test tube and resort to procedures in situ are more difficult to devise; one of these methods is that of Thomas (1961) who samples the area with sticky tape which is then transferred to agar plates. Recently Selwyn and Ellis (1972) have compared the effect of antiseptics on the skin flora.

In their work Selwyn and Ellis utilized skin excised from cadavers and at operation, in addition to a cylinder-scrub procedure, standardized swabbing, $\omega$ adhesive tape stripping, contact plates, and velvet pads. For our purposes the first two methods were $\stackrel{O}{\subset}$ inapplicable: adhesive tape would be painful on account of hair and contact plates would be difficult ${ }_{-}^{+}$ to use on the perineum; this left a choice of standardized swabbing, the cylinder-scrub, and the velvet pad $\frac{\vec{D}}{\mathrm{D}}$ technique. Selwyn and Ellis found that the use of $\frac{\mathbb{D}}{\overparen{D}}$ 


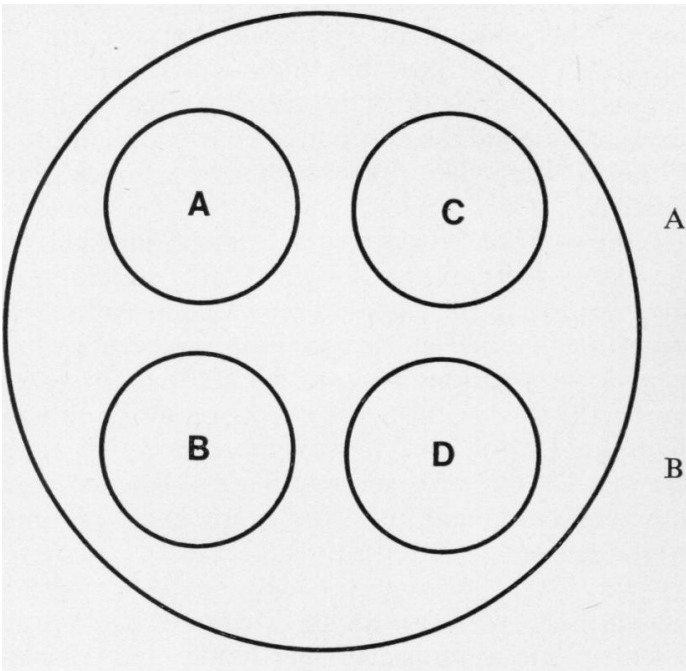

Fig 1 Diagram of a horse blood agar plate showing the four sites of application of velour pad. Bacteria present on each area were counted after 24 hours incubation

$\mathrm{A}$ and $\mathrm{C}$, initial swab; $\mathrm{B}$, after treatment with water;

$\mathrm{D}$, after treatment with antiseptic.

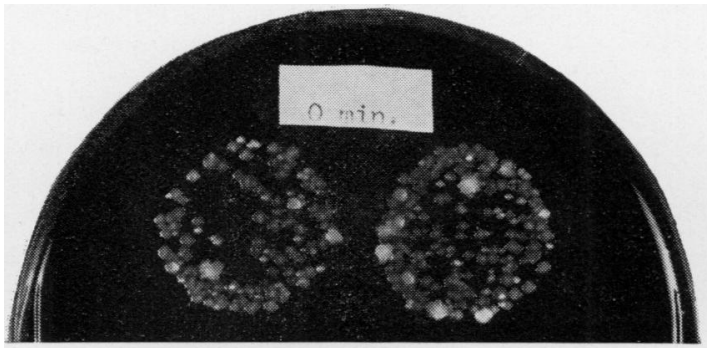

$\mathrm{X}$

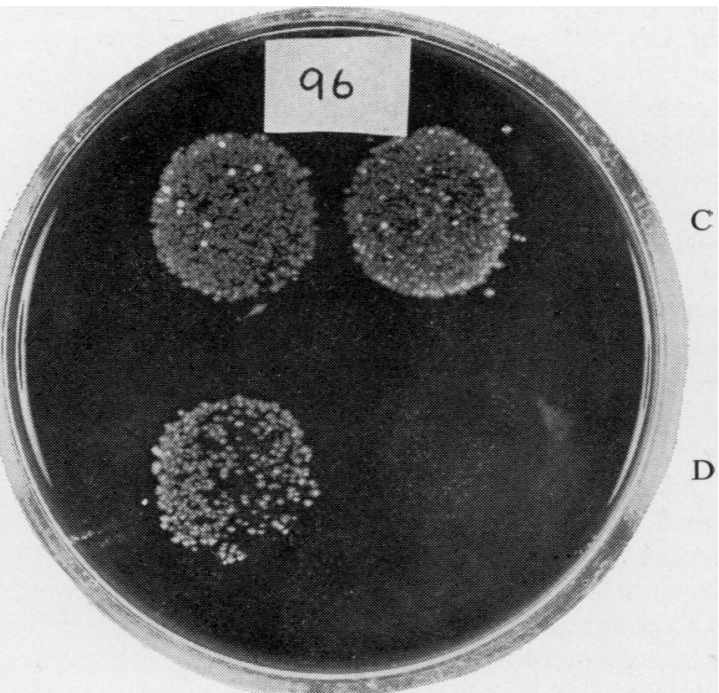

Fig 3 A successful antiseptic (site D) removes bacteria initially (site $\mathrm{C}$ ). The drop in count due to water is seen at site $\mathrm{B}$. velvet pads resulted in a low yield of bacteria, as low as $0 \cdot 1 \%$ of the yield obtained by washing off bacteria, from excised skin. Nevertheless we feel that for our purpose the use of velvet pads is valid for comparing the series of antiseptics when the procedure is applied in a standardized technique for all the antiseptics. This in turn raises a further difficulty. The superficial layers of the skin are bathed in fatty acids which may in some instances by bacteriostatic (eg, undecanoic acid) but the fat may also inhibit access of the antiseptics to the bacteria. It might be expected then that detergent or alcohol-based antiseptics would be more efficacious than those that are water based, as indeed is the case.

A large literature already exists on the investigation into the effects of antiseptics on the skin when these have been artificially contaminated (see Sykes, 1968); little has been published, however, on the effects of antiseptic on the normal flora of the skin save in regard to the cleansing of hands.

Experiments in vitro include those of McLeod and Taylor (1963) who investigated the time factor when strips of skin obtained at necropsy were artificially contaminated. Using various organisms (Staph. 
aureus, Ps. aeruginosa, Proteus, and Clostridium. welchii) against various antiseptics (iodine preparations, chlorine preparations, alcohols, and sundry antiseptics including Hibitane, Cetavlon, and phenol) they found at least half an hour's exposure to the antiseptic was required even in the case of Staphylococcus and Corynebacterium, the most frequently encountered organisms.

Also included is the work of Lowbury, Lilly, and Bull (1963) demonstrating the superiority of hexachlorophane and polyvidone iodine over dichlorophane, chlorhexidine, and halogenated alkyl/aryl phenols in removing resident Staph. aureus from hands. It was noted that detergents assisted in this.

As an example of work in vivo we can cite the investigations of Brodie (1965) and of Verdon (1961). Brodie investigated the resident flora of hands which were not artificially contaminated. His technique was exacting in that the hands were dried with gauze and the entire piece of gauze was immersed in broth. $\mathrm{He}$ observed that $E$. coli was readily removed with soap and water but that Staph.aureus was more difficult to eradicate and was more in evidence after washing than before. Of five antiseptics tested for the eradication of Staph. aureus, he was unable to choose the best from Dettol, Phisohex, or Savlon where the effects appeared to be randomly distributed. Verdon carried out trials on 11 different skin disinfecting agents used in swabbing the forearm before an injection and found $5 \%$ laurolinium to be more effective than iodine, merthiolate, and benzalkonium chloride.

The present investigation is concerned with enumerating the resident flora of the perineum under the conditions found at an episiotomy operation with a view to ascertaining the best antiseptic for preoperative skin cleansing.

As can be seen, the alcoholic solution of Dettol and Hibiscrub concentrate are very effective, the reduction in bacterial population being 100 and $98 \%$ respec- $\stackrel{0}{\overrightarrow{0}}$ tively. The efficacy of Hibiscrub appears to be aided by its detergent but high activity was still $\overrightarrow{\vec{F}}$ found after diluting it till the concentration of chlorhexidine equalled the concentration found in diluted Hibitane. The other preparations were much less effective.

In the work of Selwyn and Ellis mentioned above, these authors found that iodine in $70 \%$ ethanol and $\%$ chlorhexidine in $70 \%$ alcohol were the most effective, $\vec{\circ}$ suggesting that the vehicle used in any preparation has $\overrightarrow{-}$ an important action. The present study is in agree- $\omega$ ment with this as the most effective antiseptic was alcoholic Dettol, which was more effective than aqueous Dettol; also successful was Hibitane in a $\stackrel{\%}{\%}$ detergent base, and this was more effective than $\vec{N}$ Hibitane without detergent.

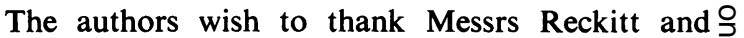
Coleman for supplies of antiseptic and photo- graphic materials, also Mr Laird of ICI Limited for the gift of Hibitane and Hibiscrub. We are grateful $\overparen{\AA}$ to Professor MacNaughton for access to his patients.

\section{References}

Brodie, J. (1965). Hand hygiene. Scot. med. J., 10, 115-125.

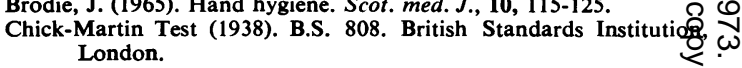

Kelsey, J. C., Beeby, M. M., and Whitehouse, C. W. (1965). capacity use-dilution test for disinfectants. Mth. Bull Mint
Hlth (Lab. Serv.), 24, 152-160.

Lowbury, E. J. L., Lilly, H. A., and Bull, J. P. (1963). Disinfection of hands : removal of resident bacteria. Brit. med. J., 1, 1251-1256.

McLeod, J. W., and Taylor, M. M. (1963). Sterilisation of the skin. Scot. med. J., 8, 234-242.

Rideal, S., and Walker, J. T. A. (1921). Approved Technique of the Rideal-Walker Test. Lewis, London.

Selwyn, S., and Ellis, H. (1972). Skin bacteria and skin disinfection reconsidered. Brit. med. J., 1, 136-140.

Sykes, G. (1968). Disinfection and Sterilisation. Spon, London.

Thomas, M. (1961). The sticky film method of detecting skin staphylococci. Mth. Bull. Minist. Hlth (Lab. Serv.), 20, 37-40.

Verdon, P. E. (1961). Efficiency tests on a series of common skin antiseptics under ward conditions, J. clin. Path., 14, 91-93. 